\title{
Offshore Wind Turbine Foundation Design as per Indian Conditions
}

\author{
Soorya Udayabhanu ${ }^{1}$, Jerin Mathew George ${ }^{2}$ \\ ${ }^{1}$ (Department of Civil Engineering, Amal Jyothi College of Engineering /MG university Kerala, India) \\ ${ }_{2}^{2}$ (Department of Civil Engineering, Amal Jyothi College of Engineering /MG university Kerala, India)
}

\begin{abstract}
Wind has been used as a source of energy since the early middle ages. Initially, windmills were used for mechanical purposes such as the milling of grain and the pumping of water. The modern wind turbine however converts the energy extracted from the wind to electrical power which can be used elsewhere. There are different types of foundation in different water depth for offshore wind turbine. Generally in India, production of wind power plant has not yet established. In this study, a location at West Cost of India has been selected. The system consists of pile, turbine tower and soil modeled as $3 D$ finite element model in ANSYS. In this paper, Preliminary design of monopile and tripod has been done to determine the pile length the as per Indian offshore condition is designed and the lateral performance of monopile and tripod supported wind turbine is determined.
\end{abstract}

Keywords: ANSYS, monopile, Offshore wind turbine, tripod

\section{Introduction}

Offshore wind power consists of construction of wind farms in bodies of water to generate electricity from wind. Better wind speeds are available at offshore compared to land, so offshore wind power's contribution in terms of electricity supplied is higher. The wind out at sea can be up to $40 \%$ more frequent and regular than on land. Offshore wind farms built to the same capacity as onshore farms are more productive. However, offshore wind farms are relatively expensive. Larger wind turbines can be built, which means that facilities a higher performance. The main disadvantage is that construction costs are high. The cost of building an offshore wind turbine can be twice as much as one on land of equal capacity. The technology behind offshore wind turbines has not yet been developed to its full potential. This means that future projects will be much more commercially feasible than those currently being developed or that are up and running.

Offshore wind is expected to grow massively over the next several decades. Most existing wind farms at sea are in northern Europe, where 5 Giga Watts have been installed. China has started pilot projects (with plans to build 30 Giga watts by 2020), and the United States has many offshore developments in the works (plans for 10 Gig watts by 2020). There are a number of reasons such that expectations are so high for offshore wind. Production of offshore wind power has not been established yet in India. To implement this preliminary studies are needed as per Indian condition. K. Abdel-Rahman et. al [1]presented finite element modelling of horizontally loaded monopile foundations for offshore wind energy converters in Germany. Aliasger Haiderali et.al [2] studied three dimensional finite element modeling of monopile for offshore wind turbines. Run Liu et.al [3] studied behavior of monopile foundations for offshore wind farms in sand. K.Abhinav et.al [4] presented uncertainty analysis of offshore wind turbines including effects of soil. Swagata Bisoi et.a [5] dynamic analysis of offshore wind turbine in clay considering soil- monopile tower interaction. The present work includes design the wind turbine as per Indian offshore condition, determine the lateral performance of monopile and tripod supported wind turbine.

\section{Design Of Offshore Wind Turbine In Indian Offshore Location}

A location at West Cost of India has been selected based on environmental data obtained from National Renewable Energy Resources (NRELT [4]. Soil profile mainly consists of sand and a few layers of silt and clay .Soil behaves as an elasto-plastic material so it is modeled as Drucker - Prager model. The Drucker-Prager yield criterion is a pressure-dependent model for determining whether a material has failed. The material of turbine tower, monopile and tripod is steel and the strength properties are modulus of elasticity, Poisons ratio and density. Turbine tower with height $81 \mathrm{~m}$ and, Diameter (D) of monopile is $6 \mathrm{~m}$.Diameter for tripod is $3 \mathrm{~m}$. 

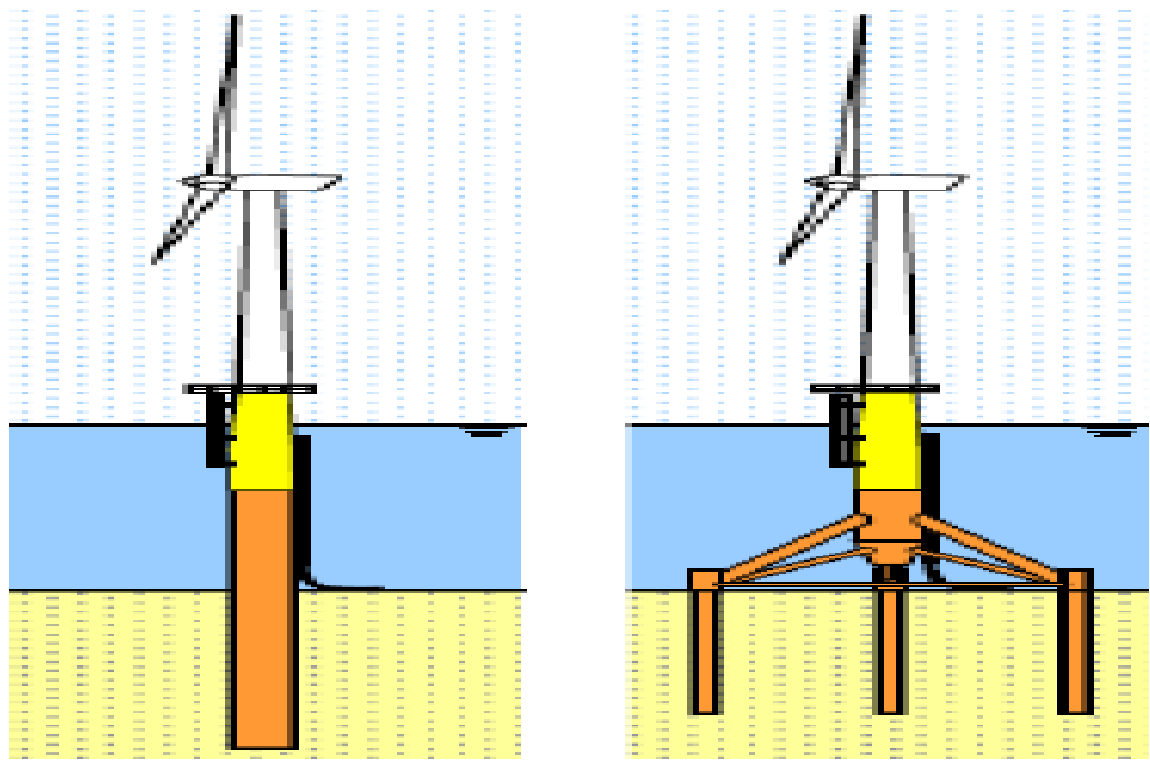

Fig 1: Monopile and Tripod Supported Offshore Wind Turbine

\subsection{Wave Loads}

\section{Loads On Turbine Tower}

For the calculation of the wave loads, the Morison formula for slender structures is used, as proposed in the DNV Offshore Standard. This load consists of two parts: an inertia part that is caused by the acceleration of the water particles and a drag part caused by the flow velocities. The drag and inertia part of the wave load will be $90^{\circ}$ out of phase. Both forces should be added as vectors for a detailed calculation. In this study this is not taken into account. The formula for the maximum force is given in equation 1.

Where, $C_{I}=$ inertia coefficient

$$
F_{\text {max }}=F_{I}+F_{D}=C_{I} K_{I} H \rho_{\text {water }} g \pi D^{2} / 4+C_{D} K_{D} H^{2} 1 / 2 \rho_{\text {wate }} r g_{D}
$$

$$
\begin{aligned}
& C_{D}=\text { drag coefficient } \\
& K_{I}=\text { correction for extent of inertia force } \\
& K_{D}=\text { correction for extent of drag force } \\
& H=\text { wave height }[\mathrm{m}] \\
& D=\text { pile diameter }
\end{aligned}
$$

\subsection{Current loads}

The current velocity will cause a load on the pile under water. This load is not constant under water, but will be highest at the surface level and zero at the seabed due to friction. The load as consequence of the current velocity can be derived using the following formula for flow around slender structures. This formula consists of a static and a dynamic part of the drag force is given in equation 2 .

Where, $C_{D}=$ static drag coefficient

$$
F_{D}=1 / 2 \rho w u 2\left(C_{D}+C_{D}^{\prime}\right) A
$$

$\mathrm{C}_{\mathrm{D}}^{\prime}=$ dynamic drag coefficient

$\mathrm{A}=$ area facing flow

\section{Modeling In ANSYS}

The ultimate purpose of a finite element analysis is to recreate mathematically the behavior of an actual engineering system. In other words the analysis must be an accurate mathematical model of physical prototype. In broadest sense this model comprises all the nodes, elements, material properties, real constants, boundary conditions and the other features that are used to represent the physical system. The three dimensional model of wind turbine with monopile and tripod are shown Fig 2 and Fig 3. The total deformation of wind turbine with monopile and tripod are shown in Fig 4 and Fig 5. The total deformation of monopile and tripod under soil are shown in Fig 6 and Fig 7. Comparison of monopile and tripod of turbine are given in Table 1. 


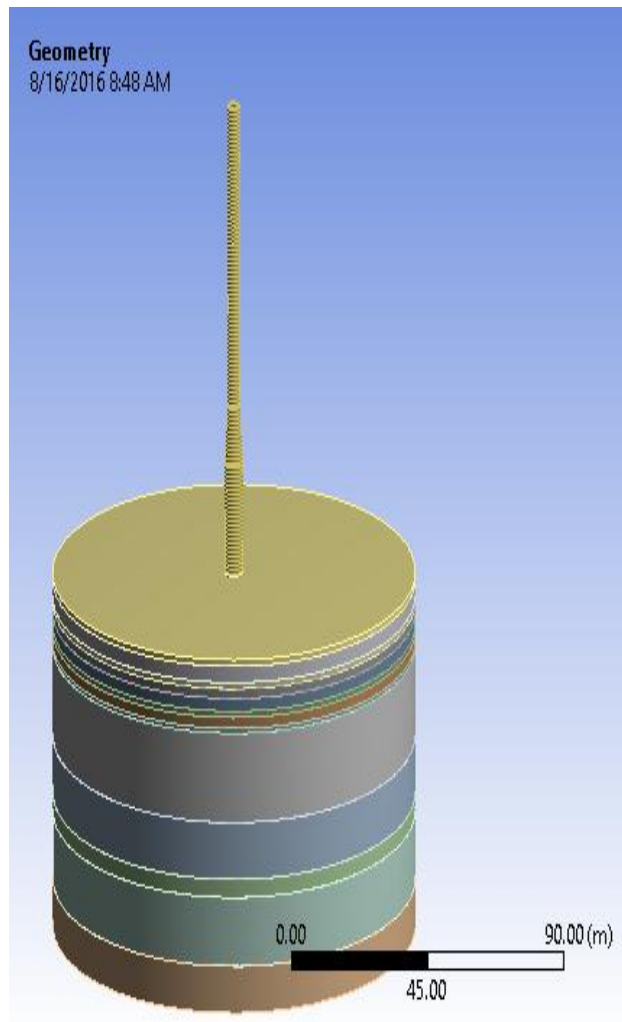

Fig 2: 3D model of monopile

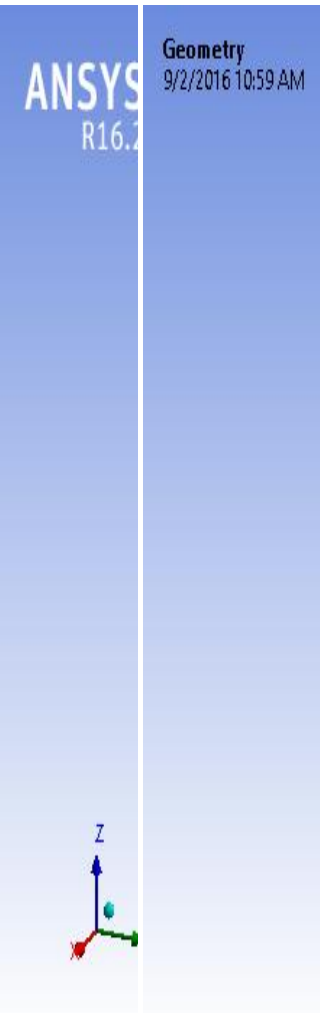

Fig 3: 3D model of tripod

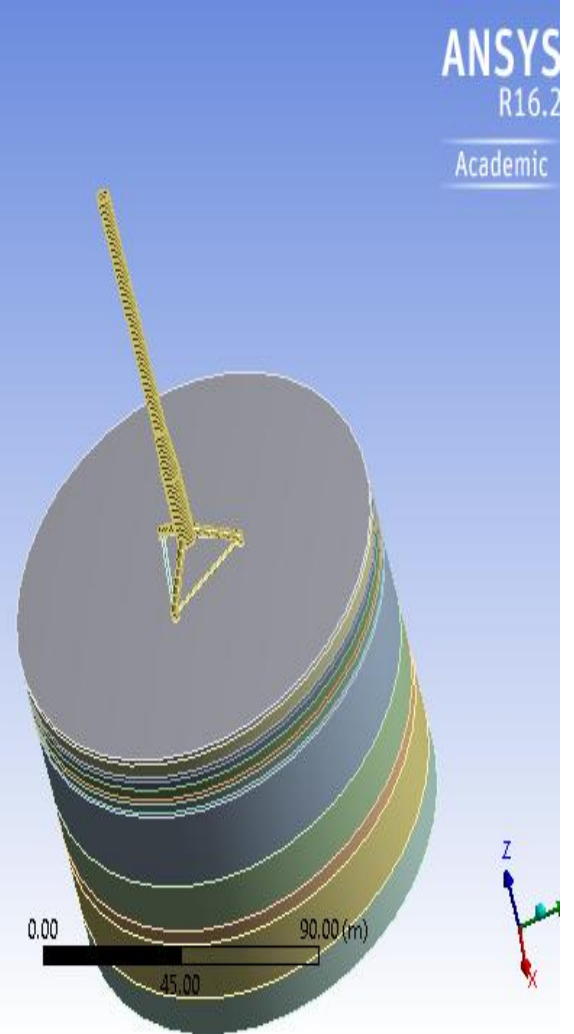

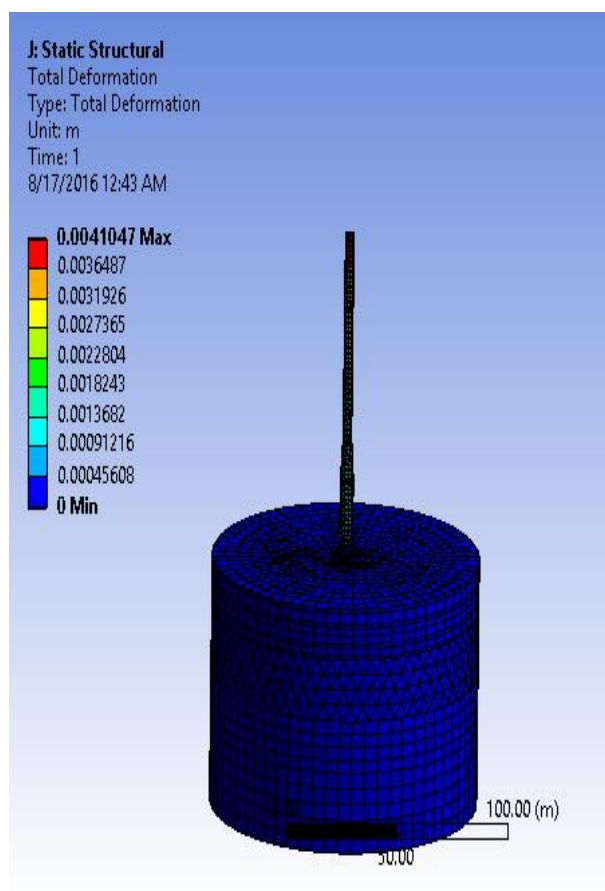

Fig 4:Total deformation of monopile
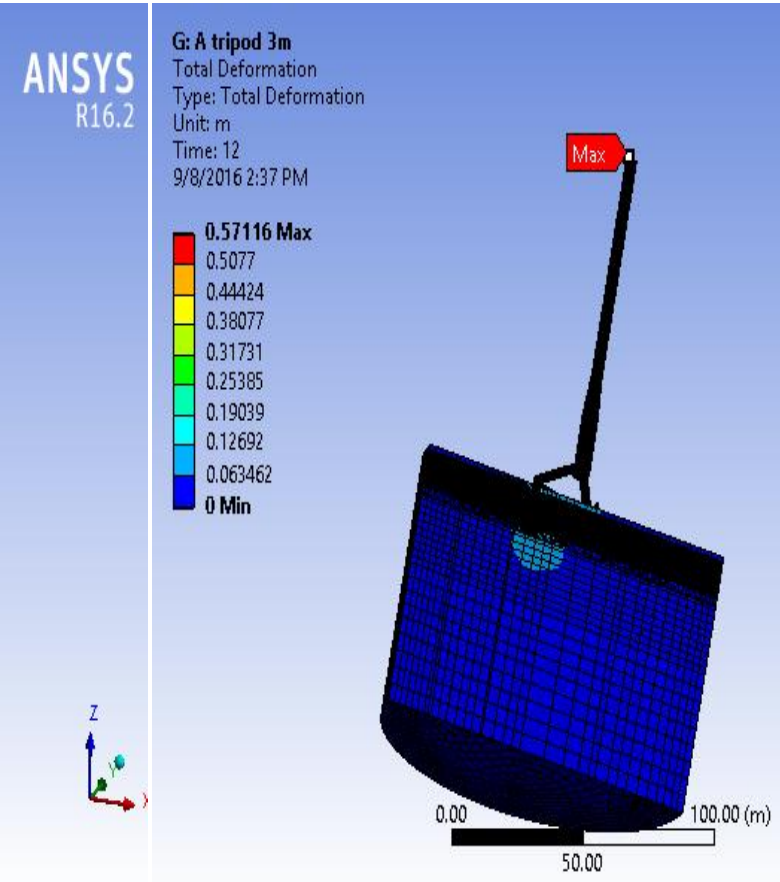

ANSYS

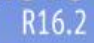

Academic

Fig 5: Total deformation of tripod 


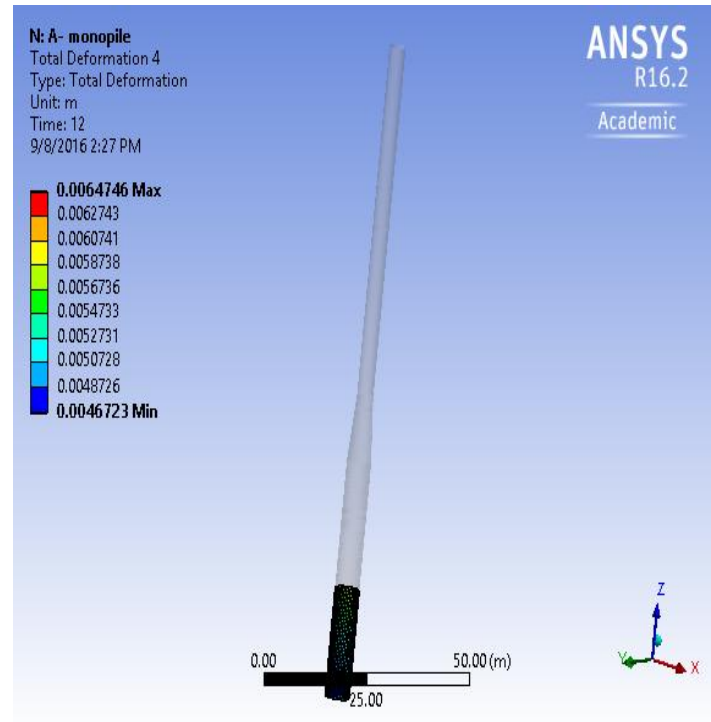

Fig 6: Total deformation of pile under soil (Monopile)

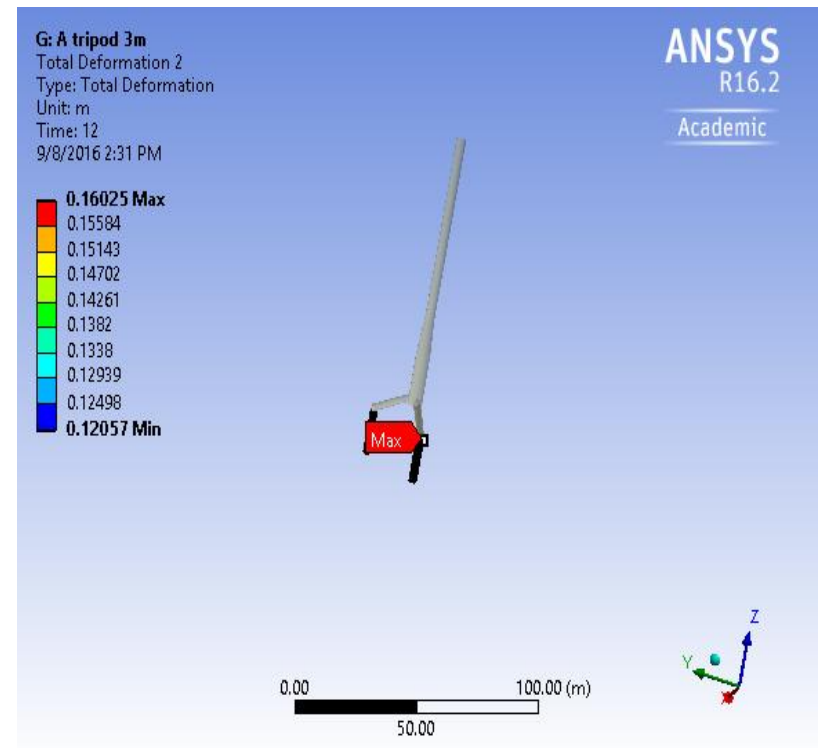

Fig 7:Total deformation of pile under soil (Tripod)

Table 1: Comparison of results

\begin{tabular}{|l|l|l|}
\hline Deformation & Monopile $(\mathbf{m m})$ & Tripod(mm) \\
\hline Total deformation & 0.0041 & 0.5711 \\
Deformation of pile under sand & 0.0062 & 0.16025 \\
\hline
\end{tabular}

\section{Conclusion}

In this project it is proposed to undertake a research study on monopile and tripod supported wind turbine in same water depth. Monopile consists of $6 \mathrm{~m}$ diameter and tripod is of $3 \mathrm{~m}$ diameter having $50 \mathrm{~mm}$ thickness. Among the software ANSYS Workbench 16.2 is found to be more suitable.

- Design of monopile and tripod supported wind turbine

A preliminary design has been done to determine the pile length .Design of monopile and tripod is designed in water depth of $25 \mathrm{~m}$ by considering wind loads, wave load and current loads. Morisons formula have been used to calculate wave and current loads. In this design, pile length for monopile is $20.47 \mathrm{~m}$ and pile length for tripod is $16 \mathrm{~m}$.

- Lateral performance of Monopile and Tripod supported wind turbine

Lateral performance has been using ANSYS software to determine the deformation. Total deformation in monopile is $0.00410 \mathrm{~mm}$ and that of tripod is $0.57116 \mathrm{~mm}$ which shows that deformation is more in tripod than monopile. Deformation of pile head in monopile is $0.062 \mathrm{~mm}$ and that of tripod is $0.16025 \mathrm{~mm}$. From the obtained results of pile head it is clear that deformation of pile head is more in tripod than monopile in same water depth.

\section{References}

[1] K. Abdel-Rahman, M. Achmus, "Finite Element Modelling of Horizontally Loaded Monopile Foundations for Offshore Wind Energy Converters in Germany" Institute of Soil Mechanics, Foundation Engineering and Waterpower Engineering, University of Hannover, Germany

[2] Aliasger Haiderali, Gopal Madabhushi, "Three Dimensional Finite Element Modelling Of Monopiles for Offshore Wind Turbines". University of Cambridge, Cambridge, UK.

[3] Run Liu; Long Zhou Ji-jian Lian, "Behavior of Monopile Foundations for Offshore Wind Farms in Sand", J. Waterway, Port, Coastal, Ocean Eng., 2016, 142(1): 04015010

[4] K.Abhinav, NilanjanSaha "Uncertainty Analysis of Offshore Wind Turbines Including Effects Of Soil"

[5] Swagata Bisoi, Sumanta Haidar, "Dynamic Analysis of offshore wind turbine in clay considering soil-monopile tower interaction", soil Dynamics and Earthquake Engineering, Vol . 63, pp. 19-35, 2014.

[6] DomenicoLombardi, Subhamoy Bhattacharya, DavidMuirWood, "Dynamic soil-structure interaction of monopile supported wind turbines in cohesive soil”, Soil Dynamics and Earthquake Engineering, vol. 49, pp. 165-180, 2013)

7] Det Norske Veritas (DNV), "Design of Offshore Wind Turbine Structures," in DNV-OS-J101, ed. Norway, 2013.

[8] Muthukkumaran,k,Sathyanarayananan,D, "Effect of Seabed Slope on Offshore Pile Lateral Behavior Under Wave Force"

[9] Run Liu; Long Zhou Ji-jian Lian, "Behavior of Monopile Foundations for Offshore Wind Farms in Sand", J. Waterway, Port, Coastal, Ocean Eng., 2016, 142(1): 04015010

[10] Ivan Depina , Thi Minh Hue Le, "Behavior of cyclically loaded monopile foundations for offshore wind turbines in heterogeneous sands." Norwegian University of Science and Technology, Department of Civil and Transport Engineering, Computers and Geotechnics 65 (2015) 266-277. 